\title{
Riesgos biológico y químico en planta de compostaje de ingenio azucarero, Valle del Cauca, Colombia
}

\section{Biological risks and chemical in composting plant of sugar mill, Valle del Cauca, Colombia}

\author{
Risco biológico e químico em planta de compostagem \\ da usina açucareira, Valle del Cauca, Colômbia
}

\author{
Iván Darío López Villalobos', Ana María Muñoz² \& Mariana Muñoz \\ ${ }^{1}$ Ingeniero Ambiental, Especialista en Administración Pública, Magister en Ingeniería Ambiental. ${ }^{2,3}$ Estudiante de \\ Salud Ocupacional en la Institución Universitaria Antonio José Camacho. Santiago de Cali, Valle, Colombia. \\ 1,2,3 Grupo de Investigación en Salud, Ambiente y Productividad - GISAP. Institución Universitaria Antonio José \\ Camacho. Santiago de Cali, Valle, Colombia. \\ 1idlopezvi@unal.edu.co, ${ }^{2}$ anmariamuoz.19@gmail.com, ${ }^{3}$ marmuoz.18@gmail.com
}

\section{Resumen}

El riesgo químico y biológico, son los principales riesgos a los que se exponen los colaboradores de la planta de compostaje del ingenio azucarero, es sin duda una posible causa de enfermedades de tipo respiratorio y de la piel, así como de enfermedades infecciosas, lo cual afecta directamente la productividad de la empresa. Se utilizó un estudio descriptivo cuya metodología se realizó en tres fases, una primera de diagnóstico e identificación de peligros, en seguida según los resultados de las listas de chequeo, se realizó una matriz DOFA, luego los árboles de problemas se convirtieron en arboles de objetivos remplazando cada uno de los problemas y consecuencias por las soluciones, así se definieron los objetivos prioritarios a emprender, para alcanzar las acciones de mejora en el proceso del compostaje. De los resultados obtenidos se resalta que el riesgo biológico tiene una interpretación de riesgo III (alto, mejorable) y representa el $55,6 \%$, mientras que el riesgo químico con una interpretación de riesgo I (muy alto, crítico) representa el 44,4\%. También debe mencionarse que la planta de compostaje presenta un déficit en las medidas de prevención y protección por el incumplimiento de la normatividad legal vigente en seguridad y salud. Es importante que la planta de compostaje empiece a gestionar el cumplimiento de lo establecido en el programa de intervención propuesto para la misma, para de esta forma disminuir la vulnerabilidad del personal expuesto a riesgos biológico y químico.

Palabras clave: enfermedad, medidas de prevención y protección, salud ambiental

\section{Abstract}

The chemical and biological risk, there are the main risks to which there are exhibited the collaborators of the plant of composting of the sugar ingenuity, undoubtedly it is possible of illnesses of respiratory type and of the skin, as well as of infectious illnesses, which affects straight the productivity of the company. There was used a descriptive study 
which methodology was realized in three phases, the first one of diagnosis and identification of dangers, immediately according to the results of the lists of checkup, a counterfoil DOFA was realized, then the problems trees turned into targets trees replacing each of the problems and consequences for the solutions, this way there were defined the priority targets to be tackled, to reach the actions of progress in the process of the composting. Of the obtained results it is highlighted that the biological risk has a risk interpretation III (tall, improvable) and represents 55,6\%, while the chemical risk with a risk interpretation I (very tall, critical) represents $44,4 \%$. Also it must be mentioned that the composting plant presents a deficit in the measurements of prevention and protection for the nonperformance of the current legal regulations in safety and health. It is important that the composting plant begins managing the fulfillment of the established in the program of intervention proposed for the same one, for thus diminish the vulnerability of the personnel exposed to biological and chemical risks.

Key-words: disease, prevention and protection measures, environmental health.

\section{Resumo}

Os riscos químico e biológico, são os principais riscos aos que colaboradores de plantas de compostagem são expostos em usinas açucareiras, isso é, sem dúvida, uma possível causa de doenças de tipo respiratório e da pele, assim como de doenças infecciosas, afetando diretamente a produtividade da empresa. Foi utilizado um estudo descritivo, onde a metodologia foi realizada em três fases, a primeira fase foi diagnóstico e identificação de perigos, posteriormente, depois dos resultados das listas de verificação, foi feita uma matriz DOFA, logo após, árvores de problemas mudaram para árvores de objetivos substituindo cada problema e suas consequências por soluções, sendo definidos assim os objetivos prioritários a cumprir para atingir as ações nas melhoras no processo da compostagem. Dos resultado obtidos destaca-se que o risco biológico tem interpretação de risco III (alto, melhorável) e representa $55,5 \%$, enquanto o risco químico, de interpretação I (muito alto, crítico) representa $44,4 \%$. Também deve ser mencionado que a planta de compostagem apresenta uma carência nas normativas de prevenção e proteção pelo não cumprimento das normativas legais atuais em segurança $e$ saúde. É importante que a planta de compostagem comece com a gestão de cumprimento do estabelecido no programa de intervenção proposto para ela e assim diminuir a vulnerabilidade do pessoal exposto a riscos tanto biológicos quanto químicos.

Palavras chave: doença, medidas de prevenção e proteção, saúde ambiental

\section{Introducción}

En numerosos sectores económicos, principalmente en la agroindustria, se encuentran agentes biológicos, los cuales casi nunca son visibles, debido a su tamaño microscópico, como lo son las bacterias, virus y hongos (levaduras y mohos) (Escobar et al., 2012). Principalmente se percibe la exposición a los microorganismos por su presencia en los residuos y por el propio proceso de compostaje (Sánchez, s.f.). También se encuentran sustancias químicas, las cuales se presentan en diferentes estados físicos dentro del ambiente de trabajo, con efectos irritantes, corrosivos, asfixiantes o tóxicos y con probabilidad de lesionar la salud de las personas que tienen contacto con ellas (Álvarez, Conti, Jiménez, Moreno \& Valderrama, 2006). Siendo su aparición una consecuencia no intencionada de la actividad laboral, como suele suceder en muchas ocasiones, la evaluación de los riesgos a los que se exponen las personas plantea mayores dificultades. Partiendo de este punto, se puede observar que existen efectos por la exposición a agentes químicos, por la generación de gases tóxicos o nocivos como el amoniaco, 
ácido sulfhídrico, metano, COV, entre otros, al remover los residuos durante el proceso $o$ al voltear las pilas (Prieto, 2008). Estos factores de riesgo, son fuentes de molestias 0 de posibles enfermedades para las personas debido al deficiente cuidado (Solans, Gadea \& Mansilla, 2008; Gutiérrez, 2011; Parra, 2003). Los procesos agroindustriales en caña de azúcar que se realizan en varias empresas del Valle del Cauca, obtienen subproductos de cosecha, que en muchos casos, son manipulados a través de plantas de compostaje para generar abonos orgánicos, presentándose diferentes agentes de riesgo para la salud de los trabajadores, como son, el riesgo biológico y químico dependiendo de la escala del proceso, que entre más extensa se presenta mayor generación de riesgo con requerimientos de medidas de control e intervención (Ruiz, 2007; Prieto, 2010). De este tipo de abono orgánico, se deriva el riesgo de que se presenten virus y bacterias, debido a su utilización, por contacto directo al tocar la tierra tratada o por inhalación de éstas durante la aplicación y diseminación del producto (Gómez, González \& Chiroles, 2004). Estos microrganismos patógenos son entre otros: Enterococus sp, Escherichia coli y la Salmonella $s p$, los cuales pueden producir enfermedades intestinales. En cualquier caso, es importante señalar que los efectos sobre la salud parecen ser debidos a la naturaleza del propio proceso de compostaje y son independientes del tipo de residuos tratados (Solans, Alonso \& Gadea, 2001; Robles, 2010; Rojas, 2014; Román, 2013; Soliva, 2008; Tabares, 2007).

Este artículo de investigación muestra la planificación de la intervención a los factores de riesgo presentes en una planta industrial de compostaje, a partir de la evaluación de las condiciones laborales (Domingo et al., 2006) en materia de prevención del proceso de planta y el hallazgo del grado de riesgo a los que están expuestos los trabajadores, y de esta forma, establecer las posibles soluciones y metodologías a las problemáticas identificadas. La necesidad de desarrollar esta investigación, es prevenir y evitar la proliferación de enfermedades en los operarios. Además, servirá como ejemplo para cumplir con la nueva normatividad en gestión de aprovechamiento de residuos sólidos, especialmente orgánicos.

\section{Metodología}

Se utilizó un estudio descriptivo que permitió recolectar datos para la descripción de la situación real. Se estableció la siguiente metodología descrita por tres fases, las cuales se interrelacionan con los objetivos específicos planteados.

\section{Fase I. Diagnóstico e identificación de peligros}

Se realizó un breve diagnóstico de la situación de la planta de compostaje industrial, en cuanto al reconocimiento de la planta de compostaje, los procesos y el tipo de materiales que existen, así como el estado sanitario de las instalaciones (según la resolución 2400), cómo se elabora el compost, con qué se cumple y qué se está incumpliendo. Además de cómo se encuentran frente al riesgo los trabajadores en materia de prevención.

Se elaboraron 2 listas de chequeo para evaluar:

1. La planta, en cuanto a los procesos y locación

2. Los trabajadores, en cuanto a vacunación (esquema de vacunación), cuáles deben ser los EPP's, la formación y capacitación

Estas listas de chequeo se evaluaron empleando la escala de Likert o método de evaluaciones sumarias (criterios de 1 a 5), donde 1 es totalmente en desacuerdo, 2 es en desacuerdo, 3 es indeciso (ni de acuerdo ni en desacuerdo), 4 es de acuerdo y 5 es totalmente de acuerdo. La lista de chequeo para los trabajadores constaba de 25 afirmaciones y la lista de chequeo para la planta constaba de 24 afirmaciones. Además, se llevó a cabo la identificación de peligros a través de una matriz de peligros, según la GTC 45 del 2012. La metodología utilizada inició con la identificación de los peligros asociados con las actividades en el lugar de trabajo, posteriormente se realizó la valoración de los riesgos: nivel de deficiencia, nivel de exposición, nivel de consecuencia, nivel de probabilidad, de donde se obtuvo la interpretación del riesgo (Índice o nivel de riesgo) y, finalmente, se establecieron medidas de control. 


\section{Fase II. Matriz DOFA y árboles de problemas}

Según los resultados de las listas de chequeo y la matriz de identificación de peligros, se realizó una matriz DOFA, utilizada como una herramienta estratégica de análisis de la situación de la planta industrial de compostaje. De esta manera se identificaron tanto las oportunidades como las amenazas y las fortalezas y debilidades a través de:

1. un análisis externo, donde se identificaron los factores externos claves para la planta. En este análisis se establecieron las oportunidades y amenazas.

2. Un análisis interno, donde se identificaron los factores internos claves para la planta. En este análisis se establecieron las fortalezas y debilidades.

A partir de los parámetros de la matriz DOFA, se estableció un árbol de problemas, donde en primera instancia se identificaron los problemas más significativos, las causas de los mismos y sus consecuencias. Las causas se dividieron en principales y secundarias para así establecer una jerarquización de las mismas, determinando los efectos del problema.

\section{Fase III. Análisis y diseño de estrategias}

Los árboles de problemas se convirtieron en arboles de objetivos, en el cual se remplazó cada uno de los problemas y consecuencias por las soluciones -medios y fines-, así se definieron los objetivos prioritarios a emprender, para alcanzar las acciones de mejora en el proceso del compostaje. De acuerdo a ello, se estableció un programa de intervención.

Población. La planta de compostaje está compuesta por 19 trabajadores directamente relacionados con el proceso del compostaje, por lo tanto para esta investigación se tomaron los 19 trabajadores como población universal, por ser un número bajo.

Criterios de inclusión

- Operarios que laboran en la planta de compostaje.

- Supervisor del proceso de compostaje.

- Microbióloga y auxiliares de microbiología del laboratorio de la planta de compostaje.

Criterios de exclusión

- Personal administrativo no relacionado con el proceso de compostaje.

- Personal de áreas distintas a la planta de compostaje que conforman el ingenio azucarero.

\section{Operacionalización de las variables}

Variables sociodemográficas.

En la Tabla 1, se muestran las diferentes variables sociodemográficas aplicadas en la lista de chequeo a los trabajadores. 
Tabla 1. Variables sociodemográficas

\begin{tabular}{|c|c|c|c|}
\hline Variables & Definición & Tipo de Variable & Medición \\
\hline Edad & $\begin{array}{l}\text { Cada uno de los períodos en que } \\
\text { se considera dividida la vida humana }\end{array}$ & $\begin{array}{l}\text { Cuantitativa discreta } \\
\text { policotómica }\end{array}$ & $\begin{array}{l}20-25 \\
30-35 \\
35-40 \\
40-45 \\
45-50\end{array}$ \\
\hline Género & $\begin{array}{l}\text { Estado social y legal que nos identifica } \\
\text { como femenino o masculino. }\end{array}$ & $\begin{array}{l}\text { Cualitativa nominal } \\
\text { Dicotómica }\end{array}$ & $\begin{array}{l}\text { Hombre } \\
\text { Mujer }\end{array}$ \\
\hline $\begin{array}{l}\text { Número de horas } \\
\text { trabajadas }\end{array}$ & $\begin{array}{l}\text { Es el tiempo diario que dedica el trabaja- } \\
\text { dor en la actividad del compostaje. }\end{array}$ & $\begin{array}{l}\text { Cuantitativa Discreta } \\
\text { dicotómica }\end{array}$ & $1 \mathrm{~h}-4 \mathrm{~h} ; 4 \mathrm{~h}-8 \mathrm{~h}$ \\
\hline Cargo & $\begin{array}{l}\text { Función de la cual una persona tiene la } \\
\text { responsabilidad en una organización, un } \\
\text { organismo o una empresa }\end{array}$ & $\begin{array}{l}\text { Cualitativa ordinal } \\
\text { policotómica }\end{array}$ & $\begin{array}{l}\text { Supervisor de área } \\
\text { Auxiliar de compostaje } \\
\text { Jefe de microbiología } \\
\text { Auxiliar de microbiología } \\
\text { Auxiliar de procesos }\end{array}$ \\
\hline Antigüedad & $\begin{array}{l}\text { Tiempo en años o meses en un determi- } \\
\text { nado cargo. }\end{array}$ & $\begin{array}{l}\text { Cuantitativa discreta } \\
\text { policotómica }\end{array}$ & $\begin{array}{l}0 \text { a } 1 \text { año } \\
1 \text { a } 5 \text { años } \\
5 \text { a } 10 \text { años }\end{array}$ \\
\hline
\end{tabular}

Variables del estudio

En las Tablas 2 y 3, se muestran las variables aplicadas en la lista de chequeo a la planta y al trabajador.

Tabla 2. Variables del estudio (listas de chequeo planta)

\begin{tabular}{l|l|l|l}
\hline Variable & \multicolumn{1}{c}{ Definición } & Tipo de Variable & \multicolumn{1}{c}{ Indicador } \\
\hline $\begin{array}{l}\text { Ubicación y can- } \\
\text { tidad de servi- } \\
\text { cios sanitarios }\end{array}$ & $\begin{array}{l}\text { Se refiere a la ubicación adecuada } \\
\text { de los servicios sanitarios y al número } \\
\text { determinado como se especifica en I } \\
\text { a norma. }\end{array}$ & $\begin{array}{l}\text { Cualitativa nominal } \\
\text { Policotómica }\end{array}$ & $\begin{array}{l}\text { Totalmente en } \\
\text { desacuerdo }\end{array}$ \\
\hline $\begin{array}{l}\text { Dotación de } \\
\text { elementos de } \\
\text { higiene personal }\end{array}$ & $\begin{array}{l}\text { Se refiere a la provisión necesaria y ade- } \\
\text { cuada de elementos de higiene personal } \\
\text { (jabón desinfectante y toalla) }\end{array}$ & $\begin{array}{l}\text { Cualitativa nominal } \\
\text { Policotómica }\end{array}$ & $\begin{array}{l}\text { De acuerdo Totalmente } \\
\text { de acuerdo }\end{array}$ \\
\hline $\begin{array}{l}\text { Existencia de } \\
\text { sitio adecuado } \\
\text { para consumo de } \\
\text { alimentos }\end{array}$ & $\begin{array}{l}\text { Se refiere a si hay un sitio en condiciones } \\
\text { óptimas para el consumo de los alimentos. }\end{array}$ & $\begin{array}{l}\text { Cualitativa nominal } \\
\text { Policotómica }\end{array}$ & $\begin{array}{l}\text { Totalmente en des- } \\
\text { acuerdo En desacuerdo } \\
\text { Indeciso De acuerdo } \\
\text { Totalmente de acuerdo }\end{array}$ \\
\hline
\end{tabular}




\begin{tabular}{|c|c|c|c|}
\hline Variable & Definición & Tipo de Variable & Indicador \\
\hline $\begin{array}{l}\text { Publicación } \\
\text { de normas de } \\
\text { bioseguridad }\end{array}$ & $\begin{array}{l}\text { Se refiere a la divulgación escrita } \\
\text { de las normas de bioseguridad. }\end{array}$ & $\begin{array}{l}\text { Cualitativa nominal } \\
\text { Policotómica }\end{array}$ & $\begin{array}{l}\text { Totalmente en des- } \\
\text { acuerdo En desacuerdo } \\
\text { Indeciso De acuerdo } \\
\text { Totalmente de acuerdo }\end{array}$ \\
\hline $\begin{array}{l}\text { Señalización de } \\
\text { riesgo químico } \\
\text { y biológico }\end{array}$ & $\begin{array}{l}\text { Existencia de las técnicas de estimula- } \\
\text { ción específicamente visual sobre riesgo } \\
\text { químico y biológico, que permite percibir } \\
\text { dichos riesgos para eludirlos. }\end{array}$ & $\begin{array}{l}\text { Cualitativa nominal } \\
\text { Policotómica }\end{array}$ & $\begin{array}{l}\text { Totalmente en des- } \\
\text { acuerdo En desacuerdo } \\
\text { Indeciso De acuerdo } \\
\text { Totalmente de acuerdo }\end{array}$ \\
\hline $\begin{array}{l}\text { Procedimiento } \\
\text { de lavado de } \\
\text { manos }\end{array}$ & $\begin{array}{l}\text { Se refiere a la existencia de un protocolo } \\
\text { donde se especifique la manera de } \\
\text { correcta del lavado de manos. }\end{array}$ & $\begin{array}{l}\text { Cualitativa nominal } \\
\text { Policotómica }\end{array}$ & $\begin{array}{l}\text { Totalmente en des- } \\
\text { acuerdo En desacuerdo } \\
\text { Indeciso De acuerdo } \\
\text { Totalmente de acuerdo }\end{array}$ \\
\hline $\begin{array}{l}\text { Protocolos para } \\
\text { manejo y } \\
\text { procesamiento } \\
\text { de residuos }\end{array}$ & $\begin{array}{l}\text { Se refiere a la existencia de un protocolo } \\
\text { donde se especifique la manera de } \\
\text { correcta para el manejo y procesamiento } \\
\text { de residuos. }\end{array}$ & $\begin{array}{l}\text { Cualitativa nominal } \\
\text { Policotómica }\end{array}$ & $\begin{array}{l}\text { Totalmente en des- } \\
\text { acuerdo En desacuerdo } \\
\text { Indeciso De acuerdo } \\
\text { Totalmente de acuerdo }\end{array}$ \\
\hline $\begin{array}{l}\text { Generación } \\
\text { de vapores orgá- } \\
\text { nicos y gases }\end{array}$ & $\begin{array}{l}\text { Se refiere a la posible emisión } \\
\text { de vapores orgánicos y gases durante } \\
\text { el proceso de compostaje }\end{array}$ & $\begin{array}{l}\text { Cualitativa nominal } \\
\text { Policotómica }\end{array}$ & $\begin{array}{l}\text { Totalmente en des- } \\
\text { acuerdo En desacuerdo } \\
\text { Indeciso De acuerdo } \\
\text { Totalmente de acuerdo }\end{array}$ \\
\hline $\begin{array}{l}\text { Monitoreo de } \\
\text { pH, temperatura, } \\
\text { humedad } \\
\text { y aireación }\end{array}$ & $\begin{array}{l}\text { Acción de vigilancia y revisión de los } \\
\text { estándares óptimos del compostaje. }\end{array}$ & $\begin{array}{l}\text { Cualitativa nominal } \\
\text { Policotómica }\end{array}$ & $\begin{array}{l}\text { Totalmente en des- } \\
\text { acuerdo En desacuerdo } \\
\text { Indeciso De acuerdo } \\
\text { Totalmente de acuerdo }\end{array}$ \\
\hline $\begin{array}{l}\text { Control } \\
\text { de olores }\end{array}$ & $\begin{array}{l}\text { Actividades encaminadas a disminuir } \\
\text { o mantener nivelados los olores emitidos } \\
\text { al ambiente por el compostaje. }\end{array}$ & $\begin{array}{l}\text { Cualitativa nominal } \\
\text { Policotómica }\end{array}$ & $\begin{array}{l}\text { Totalmente en des- } \\
\text { acuerdo En desacuerdo } \\
\text { Indeciso De acuerdo } \\
\text { Totalmente de acuerdo }\end{array}$ \\
\hline $\begin{array}{l}\text { Medición de } \\
\text { gases y vapores }\end{array}$ & $\begin{array}{l}\text { Se refiere a la acción llevada a cabo } \\
\text { para establecer los niveles en que se } \\
\text { encuentra la planta respecto a gases } \\
\text { y vapores. }\end{array}$ & $\begin{array}{l}\text { Cualitativa nominal } \\
\text { Policotómica }\end{array}$ & $\begin{array}{l}\text { Totalmente en des- } \\
\text { acuerdo En desacuerdo } \\
\text { Indeciso De acuerdo } \\
\text { Totalmente de acuerdo }\end{array}$ \\
\hline $\begin{array}{l}\text { Estudios de mi- } \\
\text { croorganismos }\end{array}$ & $\begin{array}{l}\text { Se refiere al análisis de la existencia } \\
\text { de microorganismos en el proceso de } \\
\text { compostaje }\end{array}$ & $\begin{array}{l}\text { Cualitativa nominal } \\
\text { Policotómica }\end{array}$ & $\begin{array}{l}\text { Totalmente en des- } \\
\text { acuerdo En desacuerdo } \\
\text { Indeciso De acuerdo } \\
\text { Totalmente de acuerdo }\end{array}$ \\
\hline $\begin{array}{l}\text { Existencia } \\
\text { de drenaje }\end{array}$ & $\begin{array}{l}\text { Se refiere a si hay desalojo de líquidos } \\
\text { procedentes de la descomposición de } \\
\text { los residuos }\end{array}$ & $\begin{array}{l}\text { Cualitativa nominal } \\
\text { Policotómica }\end{array}$ & $\begin{array}{l}\text { Totalmente en des- } \\
\text { acuerdo En desacuerdo } \\
\text { Indeciso De acuerdo } \\
\text { Totalmente de acuerdo }\end{array}$ \\
\hline $\begin{array}{l}\text { Uso de elemen- } \\
\text { tos de protección } \\
\text { personal }\end{array}$ & $\begin{array}{l}\text { Se refiere a la existencia o no del uso } \\
\text { de los elementos de protección personal } \\
\text { durante una actividad laboral específica }\end{array}$ & $\begin{array}{l}\text { Cualitativa nominal } \\
\text { Policotómica }\end{array}$ & $\begin{array}{l}\text { Totalmente en des- } \\
\text { acuerdo En desacuerdo } \\
\text { Indeciso De acuerdo } \\
\text { Totalmente de acuerdo }\end{array}$ \\
\hline
\end{tabular}




\begin{tabular}{l|l|l|l}
\hline Variable & \multicolumn{1}{c}{ Definición } & \multicolumn{1}{c}{ Tipo de Variable } & \multicolumn{1}{c}{ Indicador } \\
\hline $\begin{array}{l}\text { Utilización de } \\
\text { residuos de poda } \\
\text { o vegetales }\end{array}$ & $\begin{array}{l}\text { Se refiere a la utilización de residuos } \\
\text { de poda o vegetales. }\end{array}$ & $\begin{array}{l}\text { Cualitativa nominal } \\
\text { Policotómica }\end{array}$ & $\begin{array}{l}\text { Totalmente en des- } \\
\text { acuerdo En desacuerdo } \\
\text { Indeciso De acuerdo } \\
\text { Totalmente de acuerdo }\end{array}$ \\
\hline $\begin{array}{l}\text { Utilización } \\
\text { de excretas }\end{array}$ & $\begin{array}{l}\text { Se refiere al uso de deposiciones } \\
\text { de ciertos animales. }\end{array}$ & $\begin{array}{l}\text { Cualitativa nominal } \\
\text { Policotómica }\end{array}$ & $\begin{array}{l}\text { Totalmente en des- } \\
\text { acuerdo En desacuerdo } \\
\text { Indeciso De acuerdo } \\
\text { Totalmente de acuerdo }\end{array}$ \\
\hline $\begin{array}{l}\text { Utilización de vi- } \\
\text { nazas o melaza }\end{array}$ & $\begin{array}{l}\text { Se refiere al uso de los subproductos } \\
\text { líquidos por la fermentación del etanol } \\
\text { o los residuos de cristalización final del } \\
\text { azúcar, durante el proceso. }\end{array}$ & $\begin{array}{l}\text { Cualitativa nominal } \\
\text { Policotómica }\end{array}$ & $\begin{array}{l}\text { Totalmente en des- } \\
\text { acuerdo En desacuerdo } \\
\text { Indeciso De acuerdo } \\
\text { Totalmente de acuerdo }\end{array}$ \\
\hline
\end{tabular}

Tabla 3. Variables de estudio (lista de chequeo trabajador)

\begin{tabular}{|c|c|c|c|}
\hline Variable & Definición & Tipo de Variable & Indicador \\
\hline $\begin{array}{l}\text { Programa de } \\
\text { vacunación }\end{array}$ & $\begin{array}{l}\text { Se refiere a un conjunto de estrategias } \\
\text { para llevar a cabo la vacunación perti- } \\
\text { nente para proteger contra enfermeda- } \\
\text { des o infecciones de los trabajadores. }\end{array}$ & $\begin{array}{l}\text { Cualitativa nominal } \\
\text { policotómica }\end{array}$ & $\begin{array}{l}\text { Totalmente } \\
\text { en desacuerdo } \\
\text { En desacuerdo Indeciso } \\
\text { De acuerdo Totalmente } \\
\text { de acuerdo }\end{array}$ \\
\hline $\begin{array}{l}\text { Esquema de } \\
\text { vacunación }\end{array}$ & $\begin{array}{l}\text { Se refiere a qué vacunas debe tener } \\
\text { el trabajador y la dosis necesaria. }\end{array}$ & $\begin{array}{l}\text { Cualitativa nominal } \\
\text { policotómica }\end{array}$ & $\begin{array}{l}\text { Totalmente } \\
\text { en desacuerdo } \\
\text { En desacuerdo Indeciso } \\
\text { De acuerdo Totalmente } \\
\text { de acuerdo }\end{array}$ \\
\hline $\begin{array}{l}\text { Carnet de } \\
\text { vacunación }\end{array}$ & $\begin{array}{l}\text { Se refiere a la existencia del documento } \\
\text { donde está el detalle (dosis y fechas) de } \\
\text { todas las vacunas que se han aplicado. }\end{array}$ & $\begin{array}{l}\text { Cualitativa nominal } \\
\text { policotómica }\end{array}$ & $\begin{array}{l}\text { Totalmente } \\
\text { en desacuerdo } \\
\text { En desacuerdo Indeciso } \\
\text { De acuerdo Totalmente } \\
\text { de acuerdo }\end{array}$ \\
\hline $\begin{array}{l}\text { Programa de } \\
\text { exámenes me- } \\
\text { dico ocupacio- } \\
\text { nales }\end{array}$ & $\begin{array}{l}\text { Se refiere a un conjunto de estrategias } \\
\text { para llevar a cabo los exámenes } \\
\text { médicos ocupacionales pertinente } \\
\text { de los trabajadores. }\end{array}$ & $\begin{array}{l}\text { Cualitativa nominal } \\
\text { policotómica }\end{array}$ & $\begin{array}{l}\text { Totalmente } \\
\text { en desacuerdo } \\
\text { En desacuerdo Indeciso } \\
\text { De acuerdo Totalmente } \\
\text { de acuerdo }\end{array}$ \\
\hline $\begin{array}{l}\text { Realización de } \\
\text { exámenes médi- } \\
\text { cos pertinentes }\end{array}$ & $\begin{array}{l}\text { Acción de llevar a cabo las evaluaciones } \\
\text { medicas ocupacionales. }\end{array}$ & $\begin{array}{l}\text { Cualitativa nominal } \\
\text { policotómica }\end{array}$ & $\begin{array}{l}\text { Totalmente } \\
\text { en desacuerdo } \\
\text { En desacuerdo Indeciso } \\
\text { De acuerdo Totalmente } \\
\text { de acuerdo }\end{array}$ \\
\hline
\end{tabular}




\begin{tabular}{|c|c|c|c|}
\hline Variable & Definición & Tipo de Variable & Indicador \\
\hline Uso de guantes & $\begin{array}{l}\text { Se refiere a la utilización de guantes } \\
\text { durante el proceso del compostaje. }\end{array}$ & $\begin{array}{l}\text { Cualitativa nominal } \\
\text { policotómica }\end{array}$ & $\begin{array}{l}\text { Totalmente en des- } \\
\text { acuerdo } \\
\text { En desacuerdo Indeciso } \\
\text { De acuerdo Totalmente } \\
\text { de acuerdo }\end{array}$ \\
\hline $\begin{array}{l}\text { Estado de } \\
\text { los guantes }\end{array}$ & $\begin{array}{l}\text { Se refiere a las condiciones óptimas } \\
\text { de los guantes para ser utilizados. }\end{array}$ & $\begin{array}{l}\text { Cualitativa nominal } \\
\text { policotómica }\end{array}$ & $\begin{array}{l}\text { Totalmente en } \\
\text { desacuerdo } \\
\text { En desacuerdo Indeciso } \\
\text { De acuerdo Totalmente } \\
\text { de acuerdo }\end{array}$ \\
\hline $\begin{array}{l}\text { Uso de protec- } \\
\text { ción respiratoria }\end{array}$ & $\begin{array}{l}\text { Se refiere a la utilización de protección } \\
\text { respiratoria durante el proceso } \\
\text { del compostaje. }\end{array}$ & $\begin{array}{l}\text { Cualitativa nominal } \\
\text { policotómica }\end{array}$ & $\begin{array}{l}\text { Totalmente en } \\
\text { desacuerdo } \\
\text { En desacuerdo Indeciso } \\
\text { De acuerdo Totalmente } \\
\text { de acuerdo }\end{array}$ \\
\hline $\begin{array}{l}\text { Estado de la } \\
\text { protección } \\
\text { respiratoria }\end{array}$ & $\begin{array}{l}\text { Se refiere a las condiciones óptimas } \\
\text { de la protección respiratoria para ser } \\
\text { utilizada. }\end{array}$ & $\begin{array}{l}\text { Cualitativa nominal } \\
\text { policotómica }\end{array}$ & $\begin{array}{l}\text { Totalmente en } \\
\text { desacuerdo } \\
\text { En desacuerdo Indeciso } \\
\text { De acuerdo Totalmente } \\
\text { de acuerdo }\end{array}$ \\
\hline $\begin{array}{l}\text { Limpieza y } \\
\text { desinfección } \\
\text { de protección } \\
\text { respiratoria }\end{array}$ & $\begin{array}{l}\text { Se refiere a las actividades de limpieza } \\
\text { y desinfección de los respiradores }\end{array}$ & $\begin{array}{l}\text { Cualitativa nominal } \\
\text { policotómica }\end{array}$ & $\begin{array}{l}\text { Totalmente en } \\
\text { desacuerdo } \\
\text { En desacuerdo Indeciso } \\
\text { De acuerdo Totalmente } \\
\text { de acuerdo }\end{array}$ \\
\hline $\begin{array}{l}\text { Inspección } \\
\text { de protección } \\
\text { respiratoria }\end{array}$ & $\begin{array}{l}\text { Se refiere a las actividades } \\
\text { de inspección de los respiradores }\end{array}$ & $\begin{array}{l}\text { Cualitativa nominal } \\
\text { policotómica }\end{array}$ & $\begin{array}{l}\text { Totalmente en } \\
\text { desacuerdo } \\
\text { En desacuerdo Indeciso } \\
\text { De acuerdo Totalmente } \\
\text { de acuerdo }\end{array}$ \\
\hline Uso de gafas & $\begin{array}{l}\text { Se refiere a la utilización de gafas } \\
\text { durante el proceso del compostaje. }\end{array}$ & $\begin{array}{l}\text { Cualitativa nominal } \\
\text { policotómica }\end{array}$ & $\begin{array}{l}\text { Totalmente en } \\
\text { desacuerdo } \\
\text { En desacuerdo Indeciso } \\
\text { De acuerdo Totalmente } \\
\text { de acuerdo }\end{array}$ \\
\hline Estado de gafas & $\begin{array}{l}\text { Se refiere a las condiciones óptimas } \\
\text { de las gafas para ser utilizadas. }\end{array}$ & $\begin{array}{l}\text { Cualitativa nominal } \\
\text { policotómica }\end{array}$ & $\begin{array}{l}\text { Totalmente en } \\
\text { desacuerdo } \\
\text { En desacuerdo Indeciso } \\
\text { De acuerdo Totalmente } \\
\text { de acuerdo }\end{array}$ \\
\hline
\end{tabular}

\section{8}




\begin{tabular}{|c|c|c|c|}
\hline Variable & Definición & Tipo de Variable & Indicador \\
\hline $\begin{array}{l}\text { Características } \\
\text { del uniforme }\end{array}$ & $\begin{array}{l}\text { Se refiere a las cualidades requeridas } \\
\text { del uniforme para la ejecución de la } \\
\text { tarea. }\end{array}$ & $\begin{array}{l}\text { Cualitativa nominal } \\
\text { policotómica }\end{array}$ & $\begin{array}{l}\text { Totalmente en } \\
\text { desacuerdo } \\
\text { En desacuerdo Indeciso } \\
\text { De acuerdo Totalmente } \\
\text { de acuerdo }\end{array}$ \\
\hline $\begin{array}{l}\text { Estado del } \\
\text { uniforme }\end{array}$ & $\begin{array}{l}\text { Se refiere a las condiciones óptimas } \\
\text { de los uniformes para ser utilizados. }\end{array}$ & $\begin{array}{l}\text { Cualitativa nominal } \\
\text { policotómica }\end{array}$ & $\begin{array}{l}\text { Totalmente en } \\
\text { desacuerdo } \\
\text { En desacuerdo Indeciso } \\
\text { De acuerdo Totalmente } \\
\text { de acuerdo }\end{array}$ \\
\hline $\begin{array}{l}\text { Características } \\
\text { del calzado }\end{array}$ & $\begin{array}{l}\text { Se refiere a las cualidades requeridas } \\
\text { del uniforme para la ejecución } \\
\text { de la tarea. }\end{array}$ & $\begin{array}{l}\text { Cualitativa nominal } \\
\text { policotómica }\end{array}$ & $\begin{array}{l}\text { Totalmente en } \\
\text { desacuerdo } \\
\text { En desacuerdo Indeciso } \\
\text { De acuerdo Totalmente } \\
\text { de acuerdo }\end{array}$ \\
\hline $\begin{array}{l}\text { Estado del } \\
\text { calzado }\end{array}$ & $\begin{array}{l}\text { Se refiere a las condiciones óptimas } \\
\text { del calzado para ser utilizado. }\end{array}$ & $\begin{array}{l}\text { Cualitativa nominal } \\
\text { policotómica }\end{array}$ & $\begin{array}{l}\text { Totalmente en } \\
\text { desacuerdo } \\
\text { En desacuerdo Indeci- } \\
\text { so De acuerdo Total- } \\
\text { mente de acuerdo }\end{array}$ \\
\hline $\begin{array}{l}\text { Desinfección } \\
\text { y lavado de } \\
\text { uniformes }\end{array}$ & $\begin{array}{l}\text { Actividad llevada a cabo para la limpieza } \\
\text { y la eliminación de restos de compostaje } \\
\text { adheridos al uniforme. }\end{array}$ & $\begin{array}{l}\text { Cualitativa nominal } \\
\text { policotómica }\end{array}$ & $\begin{array}{l}\text { Totalmente en } \\
\text { desacuerdo } \\
\text { En desacuerdo Indeciso } \\
\text { De acuerdo Totalmente } \\
\text { de acuerdo }\end{array}$ \\
\hline $\begin{array}{l}\text { Desinfección } \\
\text { de Elementos } \\
\text { de Protección } \\
\text { Personal }\end{array}$ & $\begin{array}{l}\text { Actividad llevada a cabo para la limpieza } \\
\text { y la eliminación de restos de compostaje } \\
\text { adheridos a los elementos de protección } \\
\text { personal. }\end{array}$ & $\begin{array}{l}\text { Cualitativa nominal } \\
\text { policotómica }\end{array}$ & $\begin{array}{l}\text { Totalmente en } \\
\text { desacuerdo } \\
\text { En desacuerdo Indeciso } \\
\text { De acuerdo Totalmente } \\
\text { de acuerdo }\end{array}$ \\
\hline $\begin{array}{l}\text { Conocimiento de } \\
\text { riesgo biológico }\end{array}$ & $\begin{array}{l}\text { Se refiere a la información obtenida } \\
\text { acerca del concepto de riesgo biológico. }\end{array}$ & $\begin{array}{l}\text { Cualitativa nominal } \\
\text { policotómica }\end{array}$ & $\begin{array}{l}\text { Totalmente en } \\
\text { desacuerdo } \\
\text { En desacuerdo Indeciso } \\
\text { De acuerdo Totalmente } \\
\text { de acuerdo }\end{array}$ \\
\hline $\begin{array}{l}\text { Conocimiento de } \\
\text { riesgo químico }\end{array}$ & $\begin{array}{l}\text { Se refiere a la información obtenida } \\
\text { acerca del concepto de riesgo químico. }\end{array}$ & $\begin{array}{l}\text { Cualitativa nominal } \\
\text { policotómica }\end{array}$ & $\begin{array}{l}\text { Totalmente en } \\
\text { desacuerdo } \\
\text { En desacuerdo Indeciso } \\
\text { De acuerdo Totalmente } \\
\text { de acuerdo }\end{array}$ \\
\hline
\end{tabular}


Continuación Tabla 3

\begin{tabular}{l|l|l|l}
\hline Variable & \multicolumn{1}{c}{ Definición } & Tipo de Variable & \multicolumn{1}{c}{ Indicador } \\
\hline $\begin{array}{l}\text { Formación en } \\
\text { manipulación } \\
\text { de compostaje }\end{array}$ & $\begin{array}{l}\text { Conocimiento y experiencia } \\
\text { en la manipulación de compostaje. }\end{array}$ & $\begin{array}{l}\text { Cualitativa nominal } \\
\text { policotómica }\end{array}$ & $\begin{array}{l}\text { Totalmente } \\
\text { en desacuerdo } \\
\text { En desacuerdo Indeciso } \\
\text { De acuerdo Totalmente } \\
\text { de acuerdo }\end{array}$ \\
\hline $\begin{array}{l}\text { Programa de ca- } \\
\text { pacitación sobre } \\
\text { compostaje }\end{array}$ & $\begin{array}{l}\text { Se refiere al conjunto de procesos } \\
\text { la educación dirigidos a prolongar } \\
\text { la generación de conocimientos } \\
\text { que contribuya con el desempeño } \\
\text { eficaz del cargo. }\end{array}$ & $\begin{array}{l}\text { Cualitativa nominal } \\
\text { policotómica }\end{array}$ & $\begin{array}{l}\text { Totalmente } \\
\text { en desacuerdo }\end{array}$ \\
\hline $\begin{array}{l}\text { Programa desacuerdo Indeciso } \\
\text { de educación } \\
\text { sanitaria y } \\
\text { bioseguridad }\end{array}$ & $\begin{array}{l}\text { Se refiere al conjunto de procesos } \\
\text { yactividades relacionadas con } \\
\text { la educación dirigidos a prolongar } \\
\text { la generación de conocimientos } \\
\text { que contribuya con el desempeño } \\
\text { eficaz del cargo. }\end{array}$ & $\begin{array}{l}\text { De acuerdo Totalmente } \\
\text { de acuerdo }\end{array}$ \\
\hline $\begin{array}{l}\text { Cualitativa nominal } \\
\text { policotómica }\end{array}$ & $\begin{array}{l}\text { Totalmente } \\
\text { en desacuerdo } \\
\text { En desacuerdo Indeciso } \\
\text { De acuerdo Totalmente } \\
\text { de acuerdo }\end{array}$ \\
\hline
\end{tabular}

\section{Instrumentos de recolección de información}

De acuerdo a las fases establecidas en la metodología, se utilizaron diferentes instrumentos para cumplir con cada una de ellas. La Tabla 4 muestra los instrumentos utilizados.

Tabla 4. Instrumentos de recolección de datos

\begin{tabular}{|c|c|}
\hline Fase & Instrumento \\
\hline I & $\begin{array}{l}\text { Lista de chequeo } \\
\text { Matriz de peligros }\end{array}$ \\
\hline II & $\begin{array}{l}\text { Matriz DOFA } \\
\text { Árboles de problemas }\end{array}$ \\
\hline III & $\begin{array}{l}\text { Árboles de objetivos } \\
\text { Programa de intervención }\end{array}$ \\
\hline
\end{tabular}

\section{Resultados}

Se analizan en cada fase las condiciones laborales en materia de prevención de la planta de compostaje y de los colaboradores frente al riesgo biológico y químico existente en la planta.

\section{Diagnóstico (Fase I) \\ Planta de compostaje}

Teniendo en cuenta los resultados de la lista de chequeo que se aplicó a la planta de compostaje que se presenta en la Tabla 5, se identificó que en cuanto a instalaciones sanitarias: la planta cuenta con servicios sanitarios bien ubicados y en cantidad suficientes, aunque está pendiente la batería sanitaria para el área de operación de piscinas de lixiviados; en desacuerdo en que los servicios sanitarios están dotados con los elementos de higiene personal -jabón desinfectante y toalla-, debido a que el baño de contratistas no cuenta con la dotación de jabón desinfectante y de acuerdo en que la planta cuenta con un sitio higiénico y lejos del proceso de compostaje para el descanso y consumo de alimentos, ya que, por políticas de la empresa se debe ir al casino a consumirlos. Por lo tanto, la planta de compostaje cumple parcialmente con lo establecido en la Resolución 2400 de 1979, donde se especifica en el Título II, Capítulo II "servicios de higiene", en el artículo 17 que todos los establecimientos de trabajo deben tener un lavamanos y dotación de todos los elementos indispensables para su servicio, 
consistentes en toallas de papel, jabón y desinfectantes. Al igual que lo establecido en el artículo 25, donde se especifica que en los establecimientos de trabajo, los casinos se deberán ubicar fuera de los lugares de trabajo, y separados de otros locales, y de focos insalubres o molestos.

En normas de bioseguridad: se estuvo totalmente en desacuerdo en que las normas de bioseguridad están publicadas en un sitio visible; también, en que la planta cuenta con señalización de riesgo biológico y químico y en que la planta dispone de procedimientos escritos sobre lavado de manos, porque no se cuenta con la información divulgada de estos temas ni los medios visibles para su publicación. Así, la planta de compostaje no cumple con lo citado en el artículo 8 del decreto 1443 del 2014, donde se especifica que en prevención y promoción de riesgos laborales, el empleador debe implementar y desarrollar actividades de prevención de enfermedades laborales en el Sistema de Gestión de la Seguridad y Salud en el Trabajo SG-SST, de conformidad con la normatividad vigente. Por otro lado, se estuvo de acuerdo en que existen protocolos para manejo y procesamiento de residuos, donde la planta tiene una estandarización de éstos para que los trabajadores y las partes interesadas tengan el conocimiento oportuno del paso a paso que se lleva a cabo en los distintos procesos.

Procesos: se estuvo de acuerdo en que se generan vapores orgánicos y gases en el proceso de compostaje, debido a los procesos internos que se llevan a cabo durante la producción del compost y por la actividad del volteo de las pilas; también, en que se monitorean características como el $\mathrm{pH}$, temperatura, humedad y aireación y en que se realiza control de olores en los procesos, porque se lleva a cabo el constante control de variables del proceso y control de olores con microorganismos. Por otra parte, se estuvo totalmente de acuerdo en que la planta cuenta con un sistema de drenaje para las aguas producidas por la descomposición de los residuos al contar con canales de recolección de lixiviados para control de derrames; totalmente en desacuerdo en que se han realizado mediciones de gases y vapores como el amoniaco, ácido sulfhídrico, metano y compuestos orgánicos volátiles generados durante el proceso y en que se han realizado estudios de microorganismos como la salmonella, E.Coli y Streptococcus que pueden estar presentes en el compostaje, porque no se tiene información respecto al método de evaluación de estos agentes. Además, no se estuvo ni de acuerdo ni en desacuerdo en que los niveles de los vapores orgánicos y gases que genera la planta sobrepasan los límites permisibles, ya que no se han realizado mediciones que certifiquen estas condiciones.

Procesos específicos: se estuvo en desacuerdo en que durante la limpieza e intervención de las máquinas, durante la limpieza de trampas y la manipulación de muestras para el análisis microbiológico y fisicoquímico, se usan los elementos de protección personal correspondientes como gafas de seguridad y guantes, debido a que el personal no utiliza por completo los elementos de protección personal. Por otro lado, no se estuvo ni de acuerdo ni en desacuerdo en que durante la toma de muestras de vinaza, cachaza y compost y durante la manipulación de equipos ubicados en lechos de secado y piscina, se usan los elementos de protección personal correspondientes como gafas de seguridad y guantes porque algunas veces los operarios no utilizan sus elementos de protección personal para realizar la labor; totalmente en desacuerdo en que durante la supervisión del compostaje se usa la protección respiratoria con filtros para evitar la exposición a gases y vapores porque no cuenta con la dotación personal de dicho elemento de protección personal. Las razones por las cuales se presenta esta situación pueden estar arraigada a la carencia en los trabajadores de una cultura de cuidado y autoprotección de la salud. Por otro lado, se estuvo de acuerdo en que durante la remoción de las pilas y aplicación de vinaza se usa protección respiratoria con filtros para gases y vapores.

Materiales usados para la elaboración del compostaje: se estuvo totalmente en desacuerdo en que se utilizan excretas de animales porque no hace parte de la materia prima utilizada para la producción del compost. $Y$ totalmente de acuerdo en que se utilizan residuos de poda o cualquier residuo vegetal $y$ en que se utiliza vinaza o melaza, porque son las materias primas derivadas del proceso de producción del ingenio azucarero. 
Tabla 5. Resultados Lista de chequeo Planta

\begin{tabular}{|c|c|c|c|c|c|c|}
\hline \multicolumn{7}{|c|}{ Instalaciones Sanitarias } \\
\hline & \multicolumn{2}{|l|}{1.1} & \multicolumn{2}{|c|}{1.2} & \multicolumn{2}{|r|}{1.3} \\
\hline ITEM & \multicolumn{2}{|c|}{$\begin{array}{l}\text { Servicios sanitarios bien ubicados y en } \\
\text { cantidad suficientes }\end{array}$} & \multicolumn{2}{|c|}{$\begin{array}{l}\text { Servicios sanitarios dotados } \\
\text { de elementos de higiene } \\
\text { personal }\end{array}$} & \multicolumn{2}{|c|}{$\begin{array}{l}\text { Sitio higiénico y lejos } \\
\text { del proceso de com- } \\
\text { postaje }\end{array}$} \\
\hline VALORACIÓN & \multicolumn{2}{|l|}{4} & \multicolumn{2}{|l|}{2} & \multicolumn{2}{|r|}{4} \\
\hline \multicolumn{7}{|c|}{ Normas de bioseguridad } \\
\hline & \multicolumn{2}{|l|}{2.1} & 2.2 & \multicolumn{2}{|c|}{2.3} & 2.4 \\
\hline ITEM & \multicolumn{2}{|c|}{$\begin{array}{l}\text { Normas de Bioseguridad publicadas } \\
\text { en un sitio visible }\end{array}$} & $\begin{array}{l}\text { Señalización de } \\
\text { riesgo biológico } \\
\text { y químico }\end{array}$ & \multicolumn{2}{|c|}{$\begin{array}{l}\text { Procedimientos es- } \\
\text { critos sobre lavado } \\
\text { de manos }\end{array}$} & $\begin{array}{l}\text { Protocolos } \\
\text { para manejo y } \\
\text { procesamien- } \\
\text { to de residuos }\end{array}$ \\
\hline VALORACIÓN & \multicolumn{2}{|l|}{1} & 1 & \multicolumn{2}{|l|}{1} & 4 \\
\hline \multicolumn{7}{|c|}{ Procesos } \\
\hline & \multicolumn{2}{|l|}{3.1} & 3.2 & \multicolumn{2}{|c|}{3.3} & 3.4 \\
\hline ITEM & \multicolumn{2}{|c|}{$\begin{array}{l}\text { Generación de vapores orgánicos y } \\
\text { gases en el proceso de compostaje }\end{array}$} & $\begin{array}{l}\text { Niveles de va- } \\
\text { pores orgánicos } \\
\text { y gases sobre- } \\
\text { pasan los TLV }\end{array}$ & \multicolumn{2}{|c|}{$\begin{array}{l}\text { Monitoreo de } \mathrm{pH} \\
\text { temperatura, hume- } \\
\text { dad y aireación }\end{array}$} & $\begin{array}{l}\text { Control de } \\
\text { olores en los } \\
\text { procesos }\end{array}$ \\
\hline VALORACIÓN & \multicolumn{2}{|l|}{4} & 3 & \multicolumn{2}{|l|}{4} & 4 \\
\hline \multicolumn{7}{|c|}{ Procesos } \\
\hline & \multicolumn{2}{|l|}{3.5} & \multicolumn{2}{|c|}{3.6} & \multicolumn{2}{|r|}{3.7} \\
\hline ITEM & \multicolumn{2}{|c|}{ Mediciones de gases y vapores } & \multicolumn{2}{|c|}{ Estudios de microbiológicos } & \multicolumn{2}{|c|}{$\begin{array}{l}\text { Sistema de drenaje } \\
\text { para lixiviados }\end{array}$} \\
\hline VALORACIÓN & \multicolumn{2}{|l|}{1} & 1 & & & 5 \\
\hline & & Procesos Es & pecíficos & & & \\
\hline & 4.1 & & 4.2 & 4.3 & & 4.4 \\
\hline ITEM & $\begin{array}{l}\text { Uso de gafas de seguridad } \\
\text { y guantes/Toma de mues- } \\
\text { tras de vinaza, cachaza y } \\
\text { compost }\end{array}$ & $\begin{array}{l}\text { Uso de pro } \\
\text { toria/Remc } \\
\text { y aplicació }\end{array}$ & $\begin{array}{l}\text { tección respira- } \\
\text { ción de las pilas } \\
\text { n de vinaza }\end{array}$ & $\begin{array}{l}\text { Uso de gafa } \\
\text { seguridad y } \\
\text { tes/Manipula } \\
\text { equipos ubic } \\
\text { lecho de sec } \\
\text { piscina }\end{array}$ & $\begin{array}{l}\text { de } \\
\text { guan- } \\
\text { ción de } \\
\text { ados en } \\
\text { ado y }\end{array}$ & $\begin{array}{l}\text { Uso de gafas } \\
\text { de seguridad } \\
\text { y guantes/ } \\
\text { Limpieza e in- } \\
\text { tervención de } \\
\text { las máquinas }\end{array}$ \\
\hline VALORACIÓN & 3 & & 4 & 3 & & 2 \\
\hline & & Procesos Es & pecíficos & & & \\
\hline & 4.5 & & 4.6 & & & 4.7 \\
\hline ITEM & $\begin{array}{l}\text { Uso de gafas de seguridad } \\
\text { Limpieza de trampas }\end{array}$ & guantes/ & $\begin{array}{l}\text { Uso de gafas de } \\
\text { y guantes de nit } \\
\text { pulación de mue } \\
\text { análisis microbic } \\
\text { físicoquímico }\end{array}$ & $\begin{array}{l}\text { seguridad } \\
\text { rilo/ Mani- } \\
\text { estras para } \\
\text { lógico y }\end{array}$ & $\begin{array}{l}\text { Uso de } \\
\text { respiratc } \\
\text { sión del } \\
\text { compos }\end{array}$ & $\begin{array}{l}\text { protección } \\
\text { oria/ Supervi- } \\
\text { I proceso de } \\
\text { taje }\end{array}$ \\
\hline VALORACIÓN & 2 & & 2 & & & 1 \\
\hline & & Materis & les & & & \\
\hline & 5.1 & & 5.2 & & & 5.3 \\
\hline ITEM & $\begin{array}{l}\text { Residuos de poda o cualqui } \\
\text { vegetal/Elaboración compos }\end{array}$ & $\begin{array}{l}\text { aje residuo } \\
\text { taje }\end{array}$ & $\begin{array}{l}\text { Excretas de anir } \\
\text { boración compo }\end{array}$ & $\begin{array}{l}\text { nales/ Ela- } \\
\text { staje }\end{array}$ & $\begin{array}{l}\text { Vinaza } \\
\text { boraciór }\end{array}$ & $\begin{array}{l}\text { o melaza/ Ela- } \\
\text { n compostaje }\end{array}$ \\
\hline VALORACIÓN & 5 & & 1 & & & 5 \\
\hline
\end{tabular}




\section{Trabajadores}

De acuerdo a la lista de chequeo aplicada a los trabajadores, se presenta la Tabla 6, en la que se describe el resultado de cada aspecto.

Tabla 6. Evaluación diagnostica de higiene y seguridad a trabajadores

\begin{tabular}{ll}
\hline Aspecto & Resultado \\
Evaluado & Rado \\
\hline
\end{tabular}

Se pudo hallar que para el aspecto evaluado de que la planta cuenta con un programa de vacunación para los operarios del proceso de compostaje, el 63,16\% de los trabajadores estuvo totalmente en desacuerdo porque la empresa no cuenta con una programa de vacunación específico para la planta de compostaje y, además nunca se han realizado campañas de vacunación, Programa de por esta razón las vacunas que se tienen son por cuenta del mismo trabajador. El 21, 05\% de los vacunación trabajadores estuvo indeciso (ni de acuerdo ni en desacuerdo) porque no tienen conocimiento acerca del programa de vacunación y no han sido informados si lo hay o no. El 10,53\% de los trabajadores estuvo en desacuerdo, porque no conocen y no se han hecho programas de vacunación. Y el 5,26\% de los trabajadores estuvo de acuerdo porque el programa de vacunación existe, aunque no se han renovado las vacunas.

Para el aspecto evaluado de que la planta cuenta con un esquema de vacunación, el 68,42\% de los trabajadores estuvo totalmente en desacuerdo porque no lo conocen o porque no existe. El $21,05 \%$ de los trabajadores estuvo indeciso (ni de acuerdo ni en desacuerdo) porque no hay conocimiento de que si existe o no. El 5,26\% de los trabajadores estuvo en desacuerdo porque no se ha establecido un esquema de vacunación. Y el otro 5,26\% de los trabajadores estuvo de acuerdo porque existe un esquema en general para la empresa, aunque no aplique para la planta de compostaje.

Esquema de Vacunación

Carnet de vacunación

los carnets de vacunación.
los carnets de vacunación.
El $94,74 \%$ de los trabajadores estuvo totalmente en desacuerdo porque no se tiene el carnet de vacunación que la empresa debería adoptar de acuerdo a un esquema de vacunación específico para la planta y el $5,26 \%$ de los trabajadores estuvo en desacuerdo porque no se han hecho

Sobre la existencia de un programa de exámenes ocupacionales, el 57,89\% de los trabajadores estuvo totalmente en desacuerdo porque no lo conocen o no están informados acerca del tema. El $21,05 \%$ de los trabajadores estuvo indeciso (ni de acuerdo ni en desacuerdo) porque no saben o no conocen respecto al programa. El 15,79\% de los trabajadores estuvo en desacuerdo porque no se han hecho programas de exámenes medico ocupacionales o no se han realizado los exámenes medico ocupacionales a los trabajadores. Y el 5,26\% de los trabajadores estuvo de acuerdo porque la empresa cuenta con el programa pero falta organización en la realización de los exámenes.

Para el aspecto evaluado de que se cuenta con la realización de los exámenes medico ocupacionales pertinentes (ingreso, periódicos), el 47,37\% de los trabajadores estuvo de acuerdo porque se hacen los exámenes generales de entrada como la visiometría, la optometría, audiometría, exámenes de laboratorio pero no se han realizado las espirometrías. El 36,84\% de los trabajadores estuvo indeciso (ni de acuerdo ni en desacuerdo) porque solamente se realizan los exámenes de ingreso. El 5,26\% de los trabajadores estuvo en desacuerdo y otro 5,26\% totalmente en desacuerdo porque solamente se hacen los de ingreso y no se hacen los exámenes rutinarios y/o periódicos. Y el 5,26\% restante estuvo totalmente de acuerdo porque se realizan los exámenes completos establecidos.

En el uso de guantes impermeables tipo vaqueta para la manipulación de compostaje, el 47,37\% de los trabajadores estuvo de acuerdo porque es uno de los elementos de protección establecidos en la matriz de epp's estandarizada en la planta. El 31,58\% de los trabajadores estuvo totalmente de acuerdo porque es parte de los elementos de protección exigidos en la empresa. El 10,53\% de los trabajadores estuvo en desacuerdo y el 10,53\% restante estuvo totalmente en desacuerdo porque al pertenecer al área de laboratorio usan guantes de nitrilo y por otro lado, el supervisor no los utiliza. 
Aspecto

Evaluado

Condiciones

de los guantes:

Uso de Protección respiratoria:

Condiciones de Protección respiratoria:

Limpieza

y desinfección del respirador

Inspección y seguridad

Uso de gafas de seguridad

Condiciones de las gafas de seguridad

\section{Resultado}

Los guantes se encuentran libres de daños como rasgaduras, agujeros o deterioro, el $63,16 \%$ de los trabajadores estuvo totalmente de acuerdo porque sus guantes se encuentran en buenas condiciones para el desempeño de su trabajo. El 31,58\% de los trabajadores estuvo de acuerdo porque sus guantes están en buen estado o cumplen con las condiciones establecidas. Y el $5,26 \%$ restante de los trabajadores estuvo totalmente en desacuerdo porque no se utiliza ningún tipo de guantes por el cargo de supervisor de procesos.

Para el aspecto evaluado de que existe uso de protección respiratoria (mascara con filtros $60063 \mathrm{M})$ para vapores orgánicos y gases para la manipulación del compostaje, el 42,11\% de los trabajadores estuvo totalmente de acuerdo porque es uno de los elementos de protección establecidos en la matriz de epp's estandarizada en la planta. El 31,58\% de los trabajadores estuvo de acuerdo porque es parte de los elementos de protección exigidos en la empresa. Y el 26,32\% restante de los trabajadores estuvo totalmente en desacuerdo porque no se utiliza ningún tipo de protección respiratoria por el cargo de supervisor de procesos y para el área de laboratorio donde se utilizan tapabocas.

Con respecto al estado, si se encuentra limpia y libre de daños como rasgaduras, agujeros y distorsión, el $63,16 \%$ de los trabajadores estuvo de acuerdo porque su protección respiratoria está en buenas condiciones. El $21,05 \%$ de los trabajadores estuvo totalmente de acuerdo porque su protección respiratoria cumple con las condiciones establecidas. Y el 15,79\% restante de los trabajadores estuvo totalmente en desacuerdo porque no se utiliza el elemento de protección personal.

Para conocer si se realiza la limpieza y desinfección del respirador después de cada uso, el $47,37 \%$ de los trabajadores estuvo totalmente de acuerdo porque cumplen con las actividades de mantenimiento de sus elementos de protección personal. El 21,05\% de los trabajadores estuvo en desacuerdo porque no existe capacitación en este tipo de actividades. El 15,79\% de los trabajadores estuvo de acuerdo porque conocen la necesidad de mantener higiénicamente sus elementos de protección respiratoria. El 15,79\% restante de los trabajadores estuvo totalmente en desacuerdo porque al no utilizar la protección respiratoria, resulta obvio que no se realizan estas acciones.

Para asegurarse que funcione bien el respirador antes de usarlo, el 36,84\% de los trabajadores estuvo totalmente en desacuerdo porque no hay capacitación en el manejo de la protección respiratoria y por otro lado, porque no se utiliza en el área de laboratorio. Otro $36,84 \%$ de los trabajadores estuvo totalmente de acuerdo porque conocen el procedimiento para poder cumplir con el correcto uso de los elementos de protección personal. El 15,79\% de los trabajadores estuvo de acuerdo porque esta actividad es parte esencial del cuidado de los elementos de protección personal. El 5,26\% de los trabajadores estuvo en desacuerdo porque no conocen cómo realizar esta acción. Y el 5,26\% restante de los trabajadores estuvo indeciso (ni de acuerdo ni en desacuerdo) porque no se utiliza este tipo de elemento de protección personal por ser parte del área de laboratorio.

Sobre la existencia de uso de gafas de seguridad tipo Jackson Safety para la manipulación del compostaje, el $52,63 \%$ de los trabajadores estuvo totalmente de acuerdo porque es uno de los elementos de protección establecidos en la matriz de epp's estandarizada en la planta. El $26,32 \%$ de los trabajadores estuvo de acuerdo porque es parte de los elementos de protección exigidos en la empresa. El 15,79\% de los trabajadores estuvo totalmente en desacuerdo porque no las poseen dado que la empresa no los ha dotado de sus elementos de protección personal o porque no las usan ya que se empañan y no se ve nada y, por otro lado, porque no se utilizan en el cargo de supervisión. Y el 5,26\% restante de los trabajadores estuvo en desacuerdo porque no las utilizan en la planta.

Las gafas de seguridad se encuentran limpias y libres de daños como rayones y distorsiones, el $31,58 \%$ de los trabajadores estuvo de acuerdo porque está en buenas condiciones. El 26,32\% de los trabajadores estuvo indeciso (ni de acuerdo ni en desacuerdo) porque las gafas no se mantienen en las condiciones óptimas a partir del primer día de uso. El 21,05\% de los trabajadores estuvo totalmente de acuerdo porque sus gafas de seguridad cumplen con las condiciones establecidas. El $15,79 \%$ de los trabajadores estuvo totalmente en desacuerdo porque al no ser utilizadas no aplica este criterio. El 5,26\% restante de los trabajadores estuvo en desacuerdo porque aunque se tienen, no se usan y por lo tanto, no aplica este criterio. 
Para el aspecto evaluado de que el uniforme es de dos piezas (camisa manga larga de dril y pantalón manga larga tipo jean), el 78,95\% de los trabajadores estuvo de acuerdo porque es el

Uso de uniforme uniforme establecido por la planta para el área de compostaje. Mientras que el $21,05 \%$ de los trabajadores estuvo totalmente en desacuerdo porque en el área de laboratorio se utiliza jean, camiseta y bata y por otro lado, el supervisor utiliza ropa "casual".

El uniforme se encuentra libre de daños como rasgaduras y/o agujeros, el 57,89\% de los trabajadores estuvo totalmente de acuerdo porque su uniforme estaba en perfectas condi-

Condiciones ciones. El $36,84 \%$ de los trabajadores estuvo de acuerdo porque su uniforme cumplía con del uniforme las condiciones establecidas. Y el 5,26\% restante de los trabajadores estuvo totalmente en desacuerdo porque la ropa que se utiliza es una diferente cada día al no ser el uniforme, por lo tanto no aplica este criterio.

El calzado es cerrado, de material resistente e impermeable, el 31,58\% de los trabajadores estuvo en desacuerdo porque el calzado que les brinda la planta no son resistentes ni impermeables. El $26,32 \%$ de los trabajadores estuvo de acuerdo y otro $26,32 \%$ estuvo Uso del Calzado totalmente de acuerdo porque su calzado cumple con las condiciones establecidas. Y el $15,79 \%$ restante de los trabajadores estuvo totalmente en desacuerdo porque el calzado no es impermeable o porque no lo posee al utilizar otro tipo de calzado que no es el establecido por la empresa.

El calzado se encuentra libre de daños como rasgaduras, agujero o deterioro, el 47,37\% de los trabajadores estuvo totalmente de acuerdo porque su calzado se encontraba en buenas condiciones para su trabajo. El $31,58 \%$ de los trabajadores estuvo de acuerdo porque su calzado

Condiciones del Calzado cumplía con las condiciones físicas establecidas. El $21,05 \%$ de los trabajadores estuvo totalmente en desacuerdo porque no se utiliza el calzado establecido por la empresa, por lo tanto no aplica este criterio o porque están rotos.

Paras las manos limpias y las uñas cortas, el 68,42\% de los trabajadores estuvo totalmente de

Manos limpias acuerdo y el $10,53 \%$ estuvo de acuerdo porque cumplen con las condiciones higiénicas establey uñas cortas cidas. El 21,05\% restante de los trabajadores estuvo indeciso (ni de acuerdo ni en desacuerdo) porque se encontraban con las manos sucias por la manipulación del compostaje.

Para el aspecto evaluado de que los uniformes son lavados y desinfectados dentro de la planta,

Lavado y desinfección de uniformes el $89,47 \%$ de los trabajadores estuvo totalmente en desacuerdo y el $10,53 \%$ estuvo en desacuerdo porque no hay un área de lavado de uniformes y por lo tanto, éstos se lavan en la casa. El área para lavado se solicitó y fue denegada porque la empresa no considera que exista algún riesgo y solamente existe un área de lavado para el personal de fumigación.

Limpieza y desinfección de Elementos de protección personal EPP's

Conocimiento del riesgo biologíco

Para el aspecto de que se realiza limpieza y desinfección de los elementos de protección personal al terminal la labor, el $68,42 \%$ de los trabajadores estuvo totalmente en desacuerdo porque esta actividad se realiza muy poco o no se realiza. El 15,79\% de los trabajadores estuvo en desacuerdo porque no hay capacitación en este tipo de actividades. El 15,79\% restante de los trabajadores estuvo totalmente de acuerdo porque de una u otra forma conocen cómo realizar esta acción.

En el conocimiento del riesgo biológico en el proceso el compostaje, el $36,84 \%$ de los trabajadores estuvo totalmente en desacuerdo porque nunca les han dado información o no hay capacitación respecto al tema. El $26,32 \%$ de los trabajadores estuvo en desacuerdo porque no conocen el riesgo biológico. El $26,32 \%$ de los trabajadores estuvo de acuerdo y el $10,53 \%$ estuvo totalmente de acuerdo, porque tenían algún conocimiento previo del concepto del riesgo biológico.

En el conocimiento del riesgo químico en el proceso del compostaje, el $57,89 \%$ de los trabajadores estuvo totalmente en desacuerdo porque nunca les han dado información o capacitación respecto del tema. El $26,32 \%$ de los trabajadores estuvo de acuerdo y el 10,53\% estuvo totalmente de acuerdo, porque tenían algún conocimiento previo sobre el riesgo químico. Y el 5,26\% de los trabajadores estuvo en desacuerdo porque no conocen sobre el riesgo químico. 
En cuanto formación pertinente en la manipulación y procesamiento de compostaje, el 57,89\% de los trabajadores estuvo en totalmente en desacuerdo porque no tienen la capacitación en

Formación en manipulación de compostaje capacitación en compostaje

Programa de educación bioseguridad el tema. El 26,32\% de los trabajadores estuvo de acuerdo y el 5,26\% estuvo totalmente de acuerdo porque tienen un curso en el tema establecido. El 5,26\% de los trabajadores estuvo en desacuerdo porque les han dado pocas capacitaciones en la planta. Y el otro 5,26\% restante de los trabajadores estuvo indeciso (ni de acuerdo ni en desacuerdo) porque no saben si tienen una formación pertinente en el tema.

En la existencia de un programa de capacitación sobre compostaje (riesgos, medidas de protección, temas de higiene), el $68,42 \%$ de los trabajadores estuvo totalmente en desacuerdo porque no existe actualmente un programa de capacitación de este tipo. El 10,53\% de los trabajadores estuvo en desacuerdo porque les han dado pocas capacitaciones durante el tiempo que llevan en la planta. Otro $10,53 \%$ de los trabajadores estuvo indeciso (ni de acuerdo ni en desacuerdo) porque no tienen conocimiento. El 5,26\% de los trabajadores estuvo de acuerdo y el 5,26\% restante estuvo totalmente de acuerdo porque su apreciación es de que si existe.

En la existencia de un programa de educación en temas de bioseguridad, el $68,42 \%$ de los trabajadores estuvo totalmente en desacuerdo porque no lo han tenido. El $10,53 \%$ de los trabajadores estuvo en desacuerdo porque les han dado pocas capacitaciones durante el tiempo que llevan en la planta. El 15,79\% de los trabajadores estuvo indeciso (ni de acuerdo ni en desacuerdo) porque no lo conocen. $Y$ el 5,26\% restante de los trabajadores estuvo totalmente de acuerdo porque tienen algún conocimiento acerca del tema relacionado.

\section{Grado de riesgo al cual están expuestos los colaboradores de la planta de compostaje.}

\section{Identificación de peligros (Fase I)}

De acuerdo a la matriz de identificación de peligros, se obtuvieron los resultados de la Tabla 7.

Tabla 7. Matriz de identificación de peligros

\begin{tabular}{l|c|c}
\hline Riesgo & Interpretación de Riesgo & No. De Riesgos/lnterpretación De Riesgo \\
\hline Biológico & III & 5 \\
\hline Químico & I & 4 \\
\hline TOTAL & & 9 \\
\hline
\end{tabular}

Se pudo observar que el riesgo biológico con una interpretación de riesgo III (ALTO/situación que se puede mejorar) representa el 55,6\%, mientras que el riesgo químico con una interpretación de riesgo I (MUY ALTO/situación muy crítica) representa el $44,4 \%$, porque el riesgo biológico se encuentra presente en la mayoría de las tareas analizadas del proceso del compostaje, como lo muestra la Figura 1.

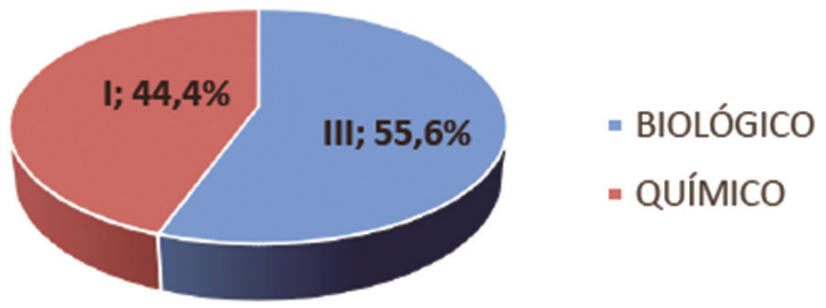

Figura 1. Interpretación del riesgo 


\section{Estrategias de intervención para controlar el riesgo biológico y químico asociado con la manipulación de compostaje}

\section{Matriz DOFA y árbol de problemas (Fase II)}

De acuerdo a los resultados de la matriz DOFA que se muestra en la Tabla 8 y teniendo en cuenta el diagnóstico de las condiciones laborales en materia de prevención de la fase I, se formuló un problema general o principal identificado en la planta de compostaje, del cual, surgieron una serie de causas y sub-causas. Estas llevan a unas posibles consecuencias, vistas desde las perspectivas tanto de salud y seguridad como legales y económicas.

Tabla 8. Matriz DOFA

\begin{tabular}{|c|c|}
\hline \multicolumn{2}{|c|}{$\begin{array}{l}\text { Planta de Compostaje } \\
\text { Matriz de Evaluación }\end{array}$} \\
\hline Fortalezas (F) & Debilidades (D) \\
\hline $\begin{array}{l}\text { 1. Estructura de la planta de compostaje. } \\
\text { 2. Protocolos para manejo y procesamiento } \\
\text { de residuos. } \\
\text { 3. Monitoreo de las características } \\
\text { físico-químicas y control de olores. } \\
\text { 4. Materia prima para la elaboración del compost. }\end{array}$ & $\begin{array}{l}\text { 1. Inexistencia de mediciones ambientales de gases } \\
\text { y vapores y estudios de microorganismos. } \\
\text { 2. Programa de vacunación y de exámenes medico ocu- } \\
\text { pacionales inespecífico para la planta de compostaje. } \\
\text { 3. Inexistencia de programa de capacitación y formación. } \\
\text { 4. Desconocimiento en aplicación de elementos } \\
\text { de protección personal adecuados para la tarea. }\end{array}$ \\
\hline Oportunidades (0) & Amenazas (A) \\
\hline $\begin{array}{l}\text { 1. Normatividad vigente en Seguridad } \\
\text { y Salud en el Trabajo. } \\
\text { 2. Convenios con laboratorios, universidades } \\
\text { u otras entidades para realizar estudios } \\
\text { ambientales. } \\
\text { 3. Compañías profesionales en la fabricación } \\
\text { de elementos de protección personal. } \\
\text { 4. Administradora de Riesgos Laborales } \\
\text { para capacitaciones al personal en riesgos. }\end{array}$ & $\begin{array}{l}\text { 1. Existencia de otras empresas generadoras de olores. } \\
\text { 2. Sanciones por el incumplimiento de la normatividad } \\
\text { legal vigente. } \\
\text { 3. Demandas por parte operarios o comunidad cercana. } \\
\text { 4. Tecnología que reduce más los riesgos } \\
\text { en otras empresas competentes. }\end{array}$ \\
\hline
\end{tabular}

\section{Análisis y diseño de estrategias (Fase III)}

De acuerdo a los resultados de la fase I y fase II, se realizó un análisis interno y externo que comprendió la identificación de las debilidades y las fortalezas presentes, donde éstos componentes se relacionaron con las oportunidades establecidas y posteriormente se generaron las estrategias FO: cruce entre las fortalezas y las oportunidades y DO: cruce entre las debilidades y oportunidades. Además, las fortalezas y las debilidades identificadas se relacionaron con las amenazas establecidas, obteniendo como resultado las estrategias FA: cruce entre las fortalezas y las amenazas y DA: cruce entre las debilidades y las amenazas, cuyo fin es el de beneficiar a los colaboradores y comunidad cercana a la planta de compostaje al diagnosticar su problemática y cómo enfrentarse a la misma a través de las estrategias formuladas. Estas estrategias se muestran en la Tablas 9 y 10.

De acuerdo a los resultados del árbol de problemas, el problema general o principal se convirtió en un objetivo general y las causas en objetivos específicos que se encaminarán en el cumplimiento de un programa de intervención integral para los riesgos especificados en la investigación, donde finalmente se pretende evitar las posibles consecuencias y alcanzar la meta de aumentar la productividad y el rendimiento laboral en la planta de compostaje. 


\section{Programa de intervención}

A partir del árbol de objetivos, se presenta el programa de intervención de la Tabla 11, a partir de un objetivo general, cuatro objetivos específicos, así como las actividades y su respectivo cronograma, segregado por año y meses para 2016 y 2017. Al final se encuentran los indicadores de evaluación con la respectiva meta según el mes.

Tabla 9. Estrategias Externas a partir de la Matriz DOFA

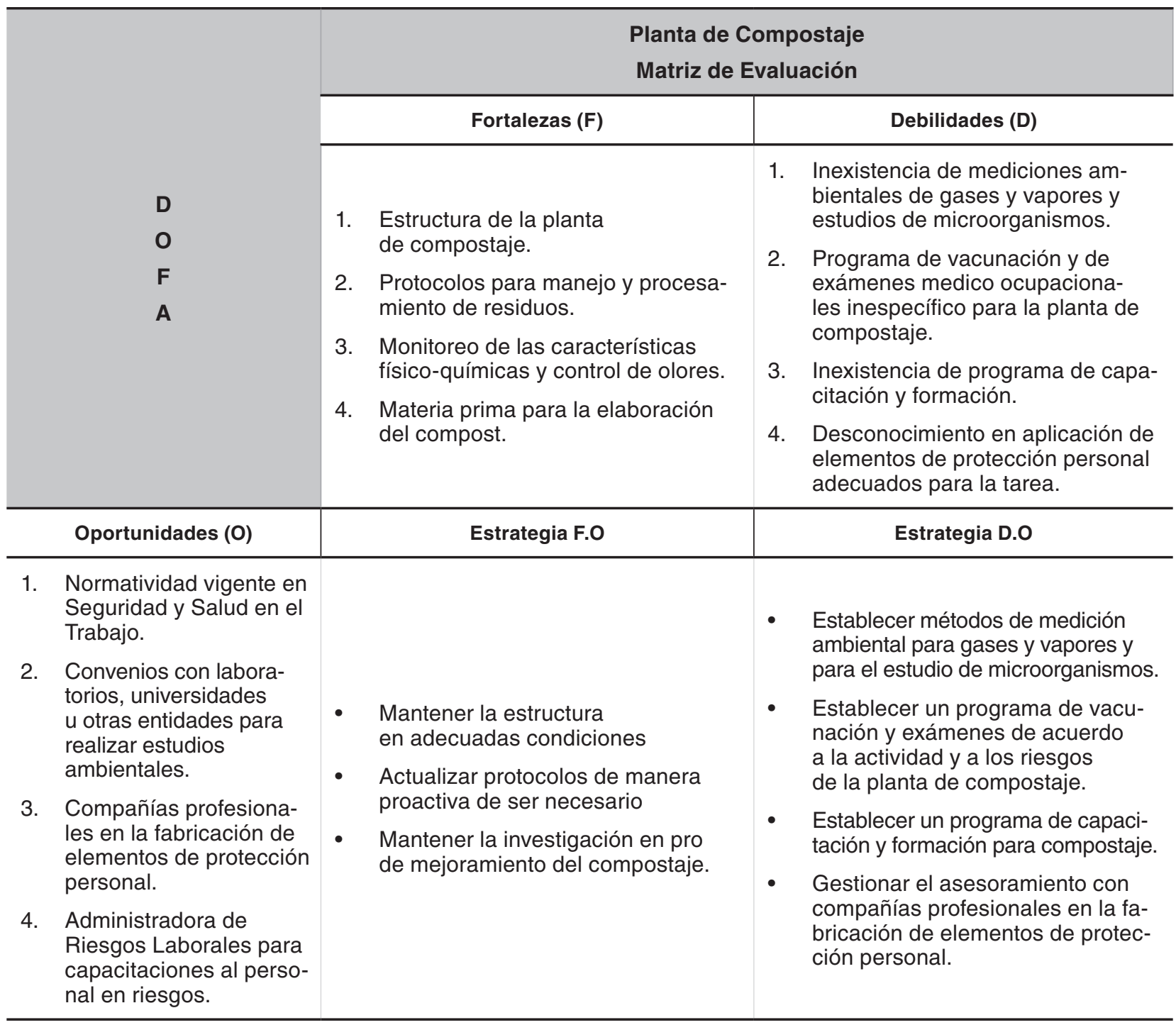


Tabla 10. Estrategias Internas a partir de la Matriz DOFA

\begin{tabular}{|c|c|c|}
\hline \multirow[b]{3}{*}{$\begin{array}{l}D \\
O \\
F \\
A\end{array}$} & \multicolumn{2}{|c|}{$\begin{array}{l}\text { Planta de Compostaje } \\
\text { Matriz de Evaluación }\end{array}$} \\
\hline & Fortalezas (F) & Debilidades (D) \\
\hline & $\begin{array}{l}\text { 1. Estructura de la planta } \\
\text { de compostaje. } \\
\text { 2. Protocolos para manejo } \\
\text { y procesamiento de residuos. } \\
\text { 3. Monitoreo de las características } \\
\text { físico-químicas y control de olores. } \\
\text { 4. Materia prima para la elaboración } \\
\text { del compost. }\end{array}$ & $\begin{array}{l}\text { 1. Inexistencia de mediciones } \\
\text { ambientales de gases y vapores } \\
\text { y estudios de microorganismos. } \\
\text { 2. Programa de vacunación y de } \\
\text { exámenes medico ocupacionales } \\
\text { inespecífico para la planta } \\
\text { de compostaje. } \\
\text { 3. Inexistencia de programa } \\
\text { de capacitación y formación. } \\
\text { 4. Desconocimiento de que si los ele- } \\
\text { mentos de protección personal son } \\
\text { los adecuados para la tarea. }\end{array}$ \\
\hline Amenazas (A) & Estrategia F.A & Estrategia D.A \\
\hline $\begin{array}{l}\text { 1. Existencia de otras } \\
\text { empresas generadoras } \\
\text { de olores. } \\
\text { 2. Sanciones por el incum- } \\
\text { plimiento de la normati- } \\
\text { vidad legal vigente. } \\
\text { 3. Demandas por parte } \\
\text { operarios o comunidad } \\
\text { cercana. }\end{array}$ & $\begin{array}{l}\text { - Mantener la estructura } \\
\text { en adecuadas condiciones } \\
\text { Seguimiento y Evaluación de } \\
\text { mediciones con registro de datos. } \\
\text { - Integrar a la comunidad y entes } \\
\text { oficiales en el manejo de emisión } \\
\text { de olores. }\end{array}$ & $\begin{array}{l}\text { - Acogerse a la normatividad legal } \\
\text { vigente para el cumplimiento de } \\
\text { los requisitos de los programas } \\
\text { de vacunación y de exámenes } \\
\text { medico ocupacionales (Resolución } \\
2346 / 2007 \text {, Resolución 10106/1989 } \\
\text { y el Decreto 614/ 1984). } \\
\text { Acogerse a la normatividad legal } \\
\text { vigente para el cumplimiento } \\
\text { de los requisitos de programas } \\
\text { de capacitación (Resolución } \\
\text { 10106/1989, Decreto 614/ 1984 } \\
\text { y el Decreto 1443/2014). } \\
\text { Gestionar estudios ambientales } \\
\text { de gases y vapores en conjunto } \\
\text { con otras empresas del sector. } \\
\text { Gestionar el asesoramiento con } \\
\text { compañías profesionales en la fa- } \\
\text { bricación de elementos de protec- } \\
\text { ción personal. }\end{array}$ \\
\hline
\end{tabular}


Tabla 11. Programa de Intervención

Objetivo General: Disminuir la vulnerabilidad del personal expuesto al riesgos biológico y químico de la planta de compostaje.

\begin{tabular}{|c|c|c|c|c|c|c|c|c|c|}
\hline \multirow{2}{*}{$\begin{array}{l}\text { OBJETIVOS } \\
\text { ESPECÍFICOS }\end{array}$} & \multirow{2}{*}{ ACTIVIDADES } & \multicolumn{5}{|c|}{ AÑO 2016} & \multirow{2}{*}{$\begin{array}{l}\text { RESPONSABLE } \\
\text { EJECUCIÓN }\end{array}$} & \multicolumn{2}{|c|}{ FECHAS } \\
\hline & & AGOS & SEPT & OCT & NOV & DIC & & INICIO & TERMINO \\
\hline \multirow{3}{*}{$\begin{array}{l}\text { Implementar } \\
\text { los elementos } \\
\text { de protección } \\
\text { personal ade- } \\
\text { cuados para } \\
\text { el proceso de } \\
\text { compostaje. }\end{array}$} & $\begin{array}{l}\text { Asesorías con } \\
\text { empresas espe- } \\
\text { cializadas en la } \\
\text { fabricación de } \\
\text { EPP's }\end{array}$ & & & & & & $\begin{array}{l}\text { Área de salud } \\
\text { ocupacional }\end{array}$ & $16-08-2016$ & $31-10-2016$ \\
\hline & $\begin{array}{l}\text { Establecimiento } \\
\text { de un programa } \\
\text { de selección } \\
\text { técnica y uso } \\
\text { de EPP's }\end{array}$ & & & & & & $\begin{array}{l}\text { Área de salud } \\
\text { ocupacional }\end{array}$ & $1-11-2016$ & $31-12-2016$ \\
\hline & $\begin{array}{l}\text { Actualización } \\
\text { de la Matriz de } \\
\text { elementos de } \\
\text { protección per- } \\
\text { sonal }\end{array}$ & & & & & & $\begin{array}{l}\text { Área de salud } \\
\text { ocupacional }\end{array}$ & $1-12-2016$ & $31-12-2016$ \\
\hline \multirow{2}{*}{$\begin{array}{l}\text { Mejorar las } \\
\text { condiciones } \\
\text { de trabajo } \\
\text { inadecuadas. }\end{array}$} & $\begin{array}{l}\text { Concientización } \\
\text { de la necesidad } \\
\text { y conveniencia } \\
\text { de los EPP's }\end{array}$ & & & & & & $\begin{array}{l}\text { Área de salud } \\
\text { ocupacional }\end{array}$ & $1-08-2016$ & $31-08-2017$ \\
\hline & $\begin{array}{l}\text { Control y super- } \\
\text { visión del uso } \\
\text { de EPP's }\end{array}$ & & & & & & $\begin{array}{l}\text { Área de salud } \\
\text { ocupacional }\end{array}$ & $16-08-2016$ & $31-08-2017$ \\
\hline \multirow{2}{*}{$\begin{array}{l}\text { Realizar } \\
\text { mediciones } \\
\text { ambientales } \\
\text { de emisiones } \\
\text { de gases y mi- } \\
\text { croorganismos } \\
\text { en el medio } \\
\text { ambiente inter- } \\
\text { no y externo. }\end{array}$} & $\begin{array}{l}\text { Actualización de } \\
\text { la matriz legal } \\
\text { de normatividad } \\
\text { concerniente a } \\
\text { riesgo químico y } \\
\text { riesgo biológico }\end{array}$ & & & & & & $\begin{array}{l}\text { Área de salud } \\
\text { ocupacional }\end{array}$ & $16-08-2016$ & $31-10-2016$ \\
\hline & $\begin{array}{l}\text { Establecimiento } \\
\text { de métodos para } \\
\text { mediciones am- } \\
\text { bientales y estu- } \\
\text { dios de análisis } \\
\text { microbiológicos }\end{array}$ & & & & & & $\begin{array}{l}\text { Área de salud } \\
\text { ocupacional } \\
\text { Gestión } \\
\text { Ambiental }\end{array}$ & $16-08-2016$ & $31-10-2016$ \\
\hline \multirow{2}{*}{$\begin{array}{l}\text { Indicadores } \\
\text { de gestión }\end{array}$} & $\begin{array}{l}\% \text { Uso EPP } \\
=\frac{N^{*} \text { de Colaboradores sin epp }}{N^{\circ} \text { Total de Colaboradores }} \times 100\end{array}$ & 50 & 70 & 80 & 90 & 100 & $\begin{array}{l}\text { Salud } \\
\text { Ocupacional }\end{array}$ & & \\
\hline & $\begin{array}{l}\text { Protocolo de } \\
\text { Aire formulado } \\
\text { Si - No }\end{array}$ & NO & NO & SI & & & $\begin{array}{l}\text { Gestión } \\
\text { Ambiental }\end{array}$ & & \\
\hline
\end{tabular}




\begin{tabular}{|c|c|c|c|c|c|c|c|c|c|c|c|c|}
\hline \multirow{2}{*}{$\begin{array}{l}\text { Objetivos } \\
\text { Específicos }\end{array}$} & \multirow{2}{*}{ Actividades } & \multicolumn{8}{|c|}{ Año 2017} & \multirow{2}{*}{$\begin{array}{l}\text { Responsable } \\
\text { Ejecución }\end{array}$} & \multicolumn{2}{|c|}{ Fechas } \\
\hline & & ENE & FEB & MAR & ABR & MAY & JUN & JUL & AGO & & Inició & Terminó \\
\hline \multirow{2}{*}{$\begin{array}{l}\text { Mejorar las } \\
\text { condiciones } \\
\text { de trabajo } \\
\text { inadecuadas. }\end{array}$} & $\begin{array}{l}\text { Capacitar en la necesidad } \\
\text { y conveniencia de los EPP's }\end{array}$ & & & & & & & & & $\begin{array}{l}\text { Área } \\
\text { de salud } \\
\text { ocupacional }\end{array}$ & $1-08-2016$ & $31-08-2017$ \\
\hline & $\begin{array}{l}\text { Control y supervisión } \\
\text { del uso de EPP's }\end{array}$ & & & & & & & & & $\begin{array}{l}\text { Área } \\
\text { de salud } \\
\text { ocupacional }\end{array}$ & $16-08-2016$ & $31-08-2017$ \\
\hline \multirow{2}{*}{$\begin{array}{l}\text { Indicadores } \\
\text { de gestión }\end{array}$} & $\%$ Uso EPP $=\frac{N^{\circ} \text { de Colaboradores sin epp }}{N^{\circ} \text { Total de Colaboradores }} \times 100$ & 100 & 100 & 100 & 100 & 100 & 100 & 100 & 100 & & & \\
\hline & $\begin{array}{l}\text { Monitoreo Ambiental } \\
\text { de emisiones (SI - No) }\end{array}$ & & SI & & & SI & & & SI & & & \\
\hline
\end{tabular}

\section{Conclusiones}

La planta de compostaje frente a los riesgos especificados, no cumple con las exigencias requeridas en la normatividad legal vigente, dado que se muestran deficiencias en la implementación de los diferentes requisitos establecidos para seguridad y salud en el trabajo.

El personal de la planta de compostaje es susceptible frente a los riesgos, debido a que las medidas de protección y prevención con las que cuentan actualmente son obsoletas o inexistentes, lo cual incrementa la probabilidad de adquirir enfermedades de diversa magnitud y severidad.

El riesgo biológico con una interpretación de riesgo III (ALTO/situación que se puede mejorar) representa el $55,6 \%$, mientras que el riesgo químico con una interpretación de riesgo I (MUY ALTO/situación muy crítica) representa el $44,4 \%$, ya que el riesgo biológico se encuentra presente en la mayoría de las tareas analizadas del proceso del compostaje.

Aunque el riesgo biológico en la planta de compostaje representa el mayor porcentaje, el riesgo químico es prioritario debido a que por su nivel de riesgo (I) no es aceptable, porque la situación es crítica y se debe realizar una intervención urgente. Dado que en la evaluación del nivel de deficiencia, de exposición, de probabilidad y de consecuencia, el riesgo químico tiene mayor valor en la determinación de cada uno de estos.
En la planta de compostaje, al no tener establecido un método de evaluación para gases, vapores y microorganismos, se evidencia el desconocimiento de los TLV'S (valores límites permisibles) de estos agentes, lo que conlleva al déficit de control de malos olores.

Los resultados hallados, pueden, no ser ajenos a la situación que presentan las plantas de compostaje en ingenios azucareros de la región suroccidental de Colombia, especialmente por el incremento del subproducto vinaza, en la necesidad de mitigar los impactos ambientales por obtención de etanol por biomasa, incrementando además, la generación de olores ofensivos, cuya situación debe medirse ambientalmente acorde a las Resoluciones 1541 de 2013 y 2087 de 2014.

El riesgo biológico al que actualmente están expuestos los colaboradores en este tipo de plantas, presenta varios aspectos en salud ambiental, en los cuales, no cumple. Se requiere actualizar e implementar a corto plazo, los planes de inmunización para los trabajadores sometidos a riesgo biológico ya que se presentan debilidades por incumplimiento parcial del Capítulo II, artículo 3 de la Resolución 2346 del 2007, donde se establece las evaluaciones médicas ocupacionales que debe realizar el empleador. Además, de lo establecido en el artículo 10, numeral 1 de la Resolución 1016 de 1989, donde se especifica la realización de los exámenes médicos como una de las actividades del subprograma de medicina preventiva y del trabajo. 


\section{Literatura citada}

1. Álvarez de la Puente, J.M. (2003). Manual de Compostaje para Agricultura Ecológica. Junta de Andalucía.

2. Álvarez Heredia, F., Conti Parra, L., Jiménez Barbosa, I., Moreno Vargas, O. \& Valderrama Montilla, F. (2006). Salud Ocupacional. Bogotá: ECOE Ediciones

3. Álvarez Heredia, F., Faizal Geagea, E. \& Valderrama, F. (2010). Riesgos biológicos y bioseguridad. ECOE Ediciones.

4. Domingo, J.L., Nadal, M., Bocio, A. \& Marti-Cid, R. (2006). Diseño de un programa de prevención de los riesgos para la salud de los trabajadores de plantas de compostaje de la fracción orgánica de residuos sólidos urbanos por exposición a contaminantes microbiológicos y químicos. Universidad Rovira i Virgili, Montcada i Reixac.

5. Escobar, N., Mora Delgado, J. \& Romero Jola, N.J. (2012). Identificación de poblaciones microbianas en compost de residuos orgánicos de fincas cafeteras de Cundinamarca. Boletín Científico Centro de Museos Museo de Historia Natural. 16 (1). 75-88.

6. Gómez Y., Gonzalez M. \& Chiroles S. (2004). Microorganismos presentes en el compost. Importancia de su control sanitario. Medio Ambiente y Desarrollo. 4 (7).

7. Gutiérrez Strauss, A.M. (2011). Guía Técnica para el análisis de exposición a factores de riesgo ocupacional para el proceso de evaluación en la calificación de origen de enfermedad. República de Colombia: Ministerio de la Protección Social.

8. ICONTEC. (2007). Norma Técnica Colombiana NTC-OHSAS 18001. "Sistema de Gestión de Seguridad y Salud. Requisitos.' Bogotá, Colombia, 24 de octubre de 2007.

9. Ministerio de Trabajo. Decreto No. 1443 de 2014. "Por el cual se dictan disposiciones para la implementación del Sistema de Gestión de la Seguridad y Salud en el Trabajo (SG-SST)." Bogotá, Colombia, 31 de julio de 2014.

10. Ministerio de Trabajo. Ley No. 1562 de 2012. "Por la cual se modifica el sistema de riesgos laborales y se dictan otras disposiciones en materia de salud ocupacional." Bogotá, Colombia, 11 de Julio de 2012.

11. Ministerio de Trabajo y Seguridad Social. Resolución No. 2400 de 1979. "Por la cual se establecen algunas disposiciones sobre vivienda, higiene y seguridad en los establecimientos de trabajo.' Bogotá, Colombia, 22 de mayo de 1979.

12. Ministerio De Vivienda, Ciudad $Y$ Territorio. Decreto No. 2981 de 2013. "Por el cual se reglamenta la prestación del servicio público de aseo." Bogotá, Colombia, 20 de diciembre de 2013.

13. Parra, M. (2003). Conceptos básicos en Salud Laboral. Oficina Internacional del Trabajo (OIT).

14. Prieto García, F., Prieto Méndez, J., Callejas Hernández, J., Román Gutiérrez, A. \& Méndez Marzo, M. (2010). Bioacumulación de arsénico en las etapas de desarrollo de la cebada maltera. Revista Mexicana de ciencias agrícolas. Recuperado de: http:// www.scielo.org.mx/scielo.php?script=sci_arttext\&pid $=$ S2007-09342010000100004
15. Prieto Rodriguez, R. (2008). Evaluación de contaminantes químicos en plantas de recuperación y tratamiento de residuos sólidos urbanos. Conferencia llevada a cabo en el IX Congreso Andaluz de Seguridad y Salud Laboral, Sevilla, España.

16. Robles Martinez, F., Leyva Ruelas, G., Zapien Espinosa, J. \& Colomer Mendoza, F. (2010). Monitoreo y análisis del proceso de compostaje en una planta de tratamiento de residuos sólidos orgánicos en la ciudad de México. Simposio Iberoamericano de Ingeniería de Residuos, Ciudad de México.

17. Rojas Corona, J. (2014). Lombricompostas caseras, calidad y propuesta para mejorar su proceso. Universidad Veracruzana, Xalapa.

18. Román, P., Martinez, M.M \& Pantoja, A. (2013). Manual de compostaje del agricultor. Organización de las Naciones Unidas para la Alimentación y la Agricultura, Santiago de Chile.

19. Ruiz, L (2007). NTP 771: Agricultura: prevención de riesgos biológicos. Instituto Nacional de Seguridad e Higiene en el Trabajo.

20. Sánchez Guillen, J.L (S.f.). Microbiología y biotecnología. Recuperado de http://www.lourdes-luengo.org/ unidadesbio/microbiologia/25Microbiologia.pdf

21. Sánchez Monedero, M.A., Roig, A., Cayuela, M.L. \& Stentiford, E.I. (2006). Emisión de bioaerosoles asociada a la gestión de residuos orgánicos. Ingeniería. 10 (1). 39-47.

22. Solans Lampurlanés, X., Alonso Espadalé, R.M \& Gadea Carrera, E (2001). NTP 597: Plantas de compostaje para el tratamiento de residuos: riesgos higiénicos. Ministerio de Trabajo y Asuntos Sociales España.

23. Solans Lampurlanés, X., Gadea Carrera, E. \& Mansilla Ordoñez, A. (2008). NTP 806: Residuos sólidos urbanos: riesgos laborales en plantas de compostaje (II). Instituto Nacional de Seguridad e Higiene en el Trabajo. España.

24. Soliva Torrento, M., López Martinez, M \& Huerta Pujol, O. (2008). Antecedentes y fundamentos del proceso de compostaje. En J. Moreno Casco (Ed.), Compostaje. (pp. 78-79). Madrid: Ediciones Mundi-Prensa.

25. Tabares Restrepo, J.E. (2007). Manual para la disposición de residuos líquidos y sólidos en los laboratorios de la coordinación inspección de calidad de la gerencia complejo Barrancabermeja. Universidad Tecnológica de Pereira, Pereira.

\section{Conflicto de Intereses \\ Los autores declaran no tener ningún conflicto de intereses}

Recibido: 30 de enero de 2016 Aceptado: 25 de marzo de 2016 